\title{
Analysis of hypoglycemic episodes in diabetics in Africans
}

\begin{abstract}
Purpose: Hypoglycemia as a management complication of diabetes mellitus (DM) is a worldwide experience. In Africa; hypoglycemia is an uncharted territory in literature. Therefore, the following questions will be addressed using Ademolus Classification of Hypoglycemia $(\mathrm{ACH})$. Which are the commonest and the least common grade of hypoglycemia in DM African patients? Which grade of hypoglycemia is seen commonly in type 1 and in type 2 diabetics?
\end{abstract}

Methods: This is a retrospective study that analyses 203documented hypoglycemic episodes in Africans with DM over 9year's period. Using a questionnaire on 50case files studied. Hypoglycemia was defined as a blood sugar of $70 \mathrm{mg} / \mathrm{dl}$ or less.

Results: By using ACH to analyze the 203hypoglycemic episodes in all type 2diabetics studied, $48.50 \%$ had grade 1 hypoglycemia, $35.93 \%$ had grade 2 hypoglycemia while $15.57 \%$ had grade 3 hypoglycemia. In all type $1 \mathrm{DM}$ studied, $30.50 \%$ had grade 1 , $33.33 \%$ had grade 2 while $36.11 \%$ had grade 3 hypoglycemia. The lowest documented hypoglycemia amongst type $2 \mathrm{DM}$ was an asymptomatic fasting blood sugar of $20 \mathrm{mg} /$ $\mathrm{dl}$ (grade 3 hypoglycemia). By using $\mathrm{ACH}$, there was no record of grade 4 hypoglycemia in both type 1 and type $2 \mathrm{DM}$ patients in this African study.

Conclusion: Asymptomatic hypoglycemia can occur in grade 3among African diabetics. Grade 1 is the commonest grade of hypoglycemia in diabetic Africans. A similar study is recommended in Americans, Europeans, Asians and all ethnic groups for possible racial diff erences or disparity in the findings of this research.
Volume 6 Issue 2 - 2019

\author{
Adegbenga B Ademolu \\ Medicine Department, Lagos State University Teaching Hospital, \\ Nigeria \\ Correspondence: Adegbenga B Ademolu, Medicine \\ Department, Lagos State University Teaching Hospital, Nigeria, \\ Tel+2348033575940,Email ademoluab@yahoo.com
}

Received: February 07, 2019 | Published: March 28, 2019

Keywords: Hypoglycemia, Ademolus Classification of Hypoglycemia, Diabetes Africans

\section{Introduction}

Hypoglycemia as a management complication of diabetes mellitus is a worldwide experience. ${ }^{1}$ Though concerted efforts have been made by endocrinologist, health workers and patients to reduce hypoglycemic episodes yet its occurrence and recurrence despite these efforts cannot be overemphasized. The glycemic thresholds for symptoms of hypoglycemia (among other responses) shift to lower plasma glucose concentrations after recent antecedent hypoglycemia, ${ }^{2-5}$ and to higher plasma glucose concentrations in patients with poorly controlled diabetes and infrequent hypoglycemia. ${ }^{6}$

Hypoglycemia in people living with diabetes mellitus in Africa is an uncharted territory in literature. To add to the existing knowledge in this area in Africa therefore, a number of questions will be addressed using Ademolus Classification of Hypoglycemia (ACH).

Table 1 shows ACH which is a product of my over 15years of rigorous work as a medical practitioner in both private and public health sector managing hypoglycemic episodes amongst others in my patients. Grade 1 has predominantly adrenergic features, grade 2 has adrenergic features with neuroglycopenic feature overlap, grade 3 has predominantly neuroglycopenic features that are majorly reversible while grade 4 has predominantly neuroglycopenic features with majorly irreversible brain damage. ${ }^{7,8}$

The questions to be addressed are what is the commonest grade of Hypoglycemia in diabetes mellitus African patients? Which is the least common grade of hypoglycemia in diabetes mellitus in Africa patients? What grade of hypoglycemia is seen commonly in type 1 diabetics? What grade of hypoglycemia is seen commonly in type 2 diabetics? How comparable is the grade of hypoglycemia seen in type 1 and type $2 \mathrm{DM}$ with the general diabetes mellitus African population?

Table I Ademolus classification hypoglycemia

\begin{tabular}{ll}
\hline Hypoglycemia & Blood sugar level mg/dl \\
\hline GRADEI (MILD) & $55-70$ \\
GRADE2 (MODERATE) & $40-54.9$ \\
GRADE3 (SEVERE) & $10-39.9$ \\
GRADE4 (VERY SEVERE) & $<10$ \\
N:B SYMPTOMATIC HYPOGLYCEMIA & \\
ABOVE 70mg/dI A SUBSET OF GRADEI & \\
N:B SYMPTOMATIC GRADE4 IS & \\
ADEMOLUSPHENOMENON &
\end{tabular}

\section{Methodology}

This is a retrospective study that analyse 203 (two hundred and three) documented hypoglycemic episodes whether symptomatic or asymptomatic in African with diabetes mellitus that were all managed as in-patients between July 2007 and October 2016 (9years and three months) in the medicine departments of Lagos State University Teaching Hospital, Ikeja, Lagos. To arrive at this 203 documented hypoglycemic episodes over the nine years period, the case file (hardware copies) of randomly selected 110known diabetes mellitus patients admitted over the study period were retrieved and studied. Of these 50(fifty) diabetics patients were found to have one or more documented hypoglycemic episodes as in-patients from which a total of 203documented hypoglycemic episodes with absolute values in $\mathrm{mg} / \mathrm{dl}$ were retrieved. 
Hypoglycemia was defined as a blood sugar of $70 \mathrm{mg} / \mathrm{dl}$ or less and $\mathrm{ACH}$ was used to analyse the data. The American Diabetes Association (ADA)/European Association for the Study of Diabetes (EASD) 2018 Classification for hypoglycaemia (see Table 2) was also used to analyse the data. ${ }^{9}$

Table 2 American diabetes association/European association for the study of diabetes 2018 classification of hypoglycaemia

\section{Diabetes (EASD) 2018 Classification for hypoglycaemia}

\begin{tabular}{ll} 
Levels & Glycemic criteria/description \\
Level I & $\begin{array}{l}\text { Glucose }<70 \mathrm{mg} / \mathrm{dL}(3.9 \mathrm{mmol} / \mathrm{L}) \text { and glucose } \geq 54 \mathrm{mg} / \mathrm{dL} \\
(3.0 \mathrm{mmol} / \mathrm{L})\end{array}$ \\
Level 2 & $\begin{array}{l}\text { Glucose }<54 \mathrm{mg} / \mathrm{dL}(3.0 \mathrm{mmol} / \mathrm{L}) \\
\text { Level } 3\end{array} \quad \begin{array}{l}\text { A severe event characterized by altered mental and/or physical } \\
\text { status requiring assistance. }\end{array}$ \\
\hline
\end{tabular}

All check of blood sugar whether random or in fasting state was with the use of a glucometer

A pretested and validated questionnaire was drawn and administered as a tool to extract relevant information from each of the relevant 50case files of these admitted African with diabetes mellitus. The questionnaire is in two sections, Section a retrieved demographic data from the case file excluding names. Section B retrieves divers information on each hypoglycemic episodes including absolute value of hypoglycemia in $\mathrm{mg} / \mathrm{dl}$, date of occurrence, time of occurrence, type of diabetes mellitus patient is being managed for, clinical features at time of occurrence (if documented) drug patient is on ,insulin or glucose lowering agents or both, comorbidity amongst other questions.

The inclusion criteria include known diabetes mellitus patients currently on treatment with either insulin or glucose lowering agents or both, also one or more in-patient admission period for diabetes mellitus or related complication was a criteria.

Exclusion criteria include known diabetic patients on out patients with no documented history of hospital admission, documented hypoglycemia in non diabetics was also excluded, and in-patients diabetic's admissions without single documented episodes of hypoglycemia were excluded. None of the patients studied were managed in the intensive care unit.

\section{The data were manually analysed}

The merit/strength of this study is that all the 203episodes of documented hypoglycemia studied were taken and recorded by health workers in in-patients settings during routine check or 6 or 8 point blood sugar check. No case of probable hypoglycemia or reported hypoglycemic episodes which is/are debatable or subjective were used, this was why diabetic with only outpatient attendance were excluded in this study.

Also chances of missing episodes of hypoglycemia during hypoglycemia unawareness was reduced as the blood sugar check was done routinely daily at intervals by health workers.

\section{Results}

It should be noted that the analysis is that of 203documented hypoglycemic episodes in 50diabetics. The male to female ratio was 1:1.43 of the diabetics had type 2 while 7 had type 1 DM.
The age range of the patients studied over the nine years 3months periods was 18 to 95 years, the age range among those with type 1 was 18-56years, while among the type 2 it was 38-95years.

The type 2 diabetics involved in this study had a total of 167 documented episodes of hypoglycemia while those with type 1 had 36documented episodes. In all these Africans, the average documented hypoglycemic episodes per patient were 4episodes. Among the type 2 patients, the average hypoglycemic episode is equally approximately 4 episodes per diabetics, while among the type 1 the average hypoglycaemic episode is 5 per diabetic.

The lowest documented hypoglycemia amongst type 1 diabetics in this study was $21 \mathrm{mg} / \mathrm{dl}$ (grade 3hypoglycemia) which was a nocturnal hypoglycemia that occurred at 1:00am while the lowest documented hypoglycemia amongst type 2 was $20 \mathrm{mg} / \mathrm{dl}$ (grade 3 hypoglycemia) which was a fasting blood sugar documented at 6:00am. There was no record of grade 4hypoglycemia in both type 1 and type 2 diabetes mellitus patients in this African study.

Now by using Ademolus Classification of Hypoglycemia to analyse the 203 hypoglycemic episodes, $45.32 \%$ had grade 1hypoglycemia, $35.47 \%$ had grade 2hypoglycemia while $19.21 \%$ had grade 3 hypoglycemia (Figure 1). With respect to the 167 episodes seen in type 2 diabetic, $48.50 \%$ had grade 1 hypoglycemia, $35.93 \%$ had grade 2 hypoglycemia while $15.57 \%$ had grade 3 hypoglycemia (Figure 2).

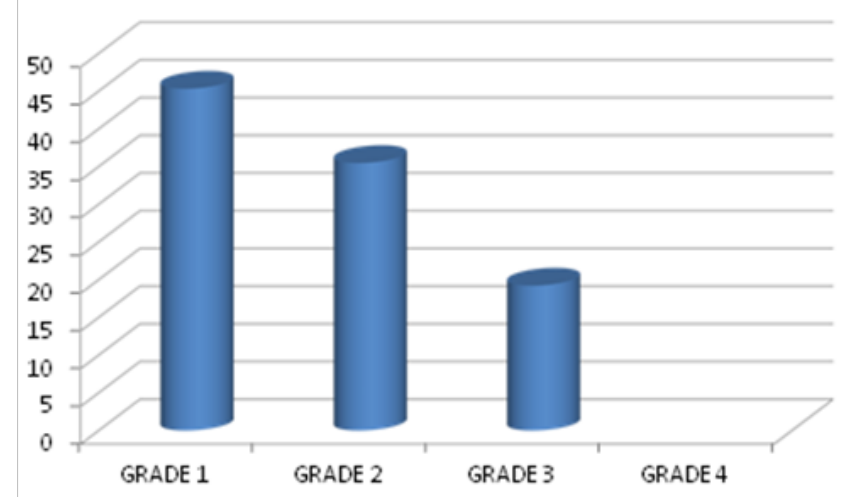

Figure I Percentage distribution hypoglycaemic episodes in diabetics (Both type I and 2) in Africans. ( $n=203)$

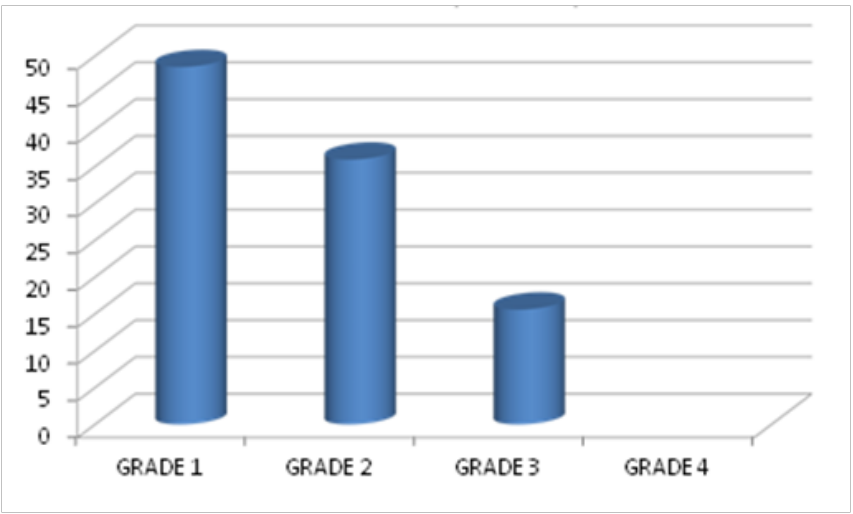

Figure 2 Percentage distribution hypoglycaemic episodes in type 2 diabetics in Africans. $(n=167)$

A total of 127 hypoglycemic episodes were recorded in type 2 diabetes mellitus patients on insulin therapy alone. Of these $53.54 \%$ 
had grade 1 hypoglycemia, $31.50 \%$ had grade 2 hypoglycemia while $14.96 \%$ had grade 3 hypoglycemia (Figure 3 ).

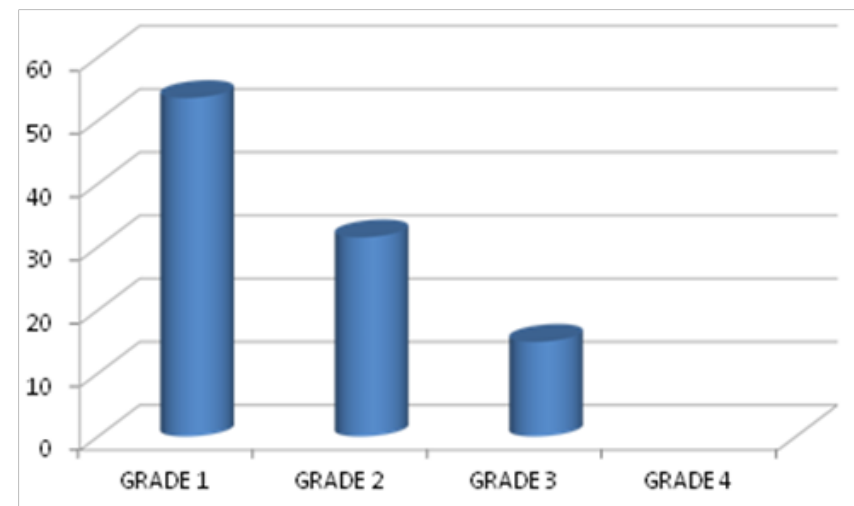

Figure 3 Percentage distribution hypoglycaemic episodes in type 2 diabetics on insulin therapy alone in Africans. $(n=127)$

The type 2 diabetics on insulin and glucose lowering agents had 39 episodes of hypoglycemia recorded out of which $33.33 \%$ had grade 1hypoglycemia, $48.72 \%$ had grade 2 hypoglycemia while $17.95 \%$ had grade 3 hypoglycemia (Figure 4).

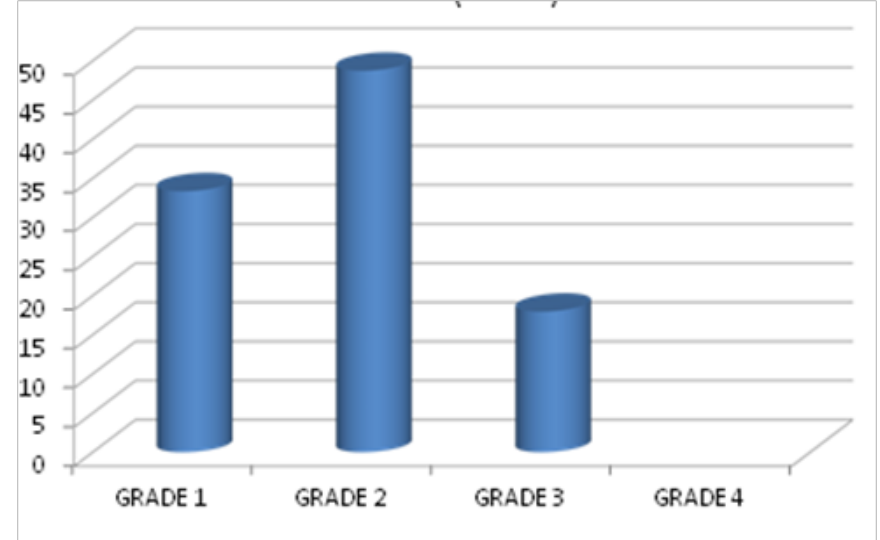

Figure 4 Percentage distribution hypoglycaemic episodes in type 2 diabetics on insulin therapy and oral hypoglycaemic agents in Africans. $(n=39)$

Type 2 diabetics on glucose lowering agents alone could not be characterised by percentages of grade present as only one diabetic with one episode of hypoglycemia (grade 3) was involved in the study.

The patients with type 1 diabetes mellitus had 36 hypoglycemic episodes, $30.50 \%$ of these were grade $1,33.33 \%$ were grade 2 while $36.11 \%$ were grade 3 hypoglycemia (Figure 5).

There was no episode of grade 4hypoglycemia in both type 1 and type 2 diabetes mellitus Africans patients involved in this study.

By using the ADA/EASD 2018 classification of hypoglycemia, only 197episodes of hypoglycemia met the classification definition of hypoglycemia as 6episodes had $70 \mathrm{mg} / \mathrm{dl}$ and did not qualified for hypoglycemia as defined by the ADA/EASD 2018 Classification of hypoglycemia as $<70 \mathrm{mg} / \mathrm{dl}$.

Analytically using ADA/EASD classification to analyse all the 197 hypoglycemic episodes studied, 77 (39.09\%) hypoglycemic episodes had level 1 hypoglycemia, $90(45.69 \%)$ had level 2 hypoglycemia while $30(15.22 \%)$ had level 3 hypoglycemia.

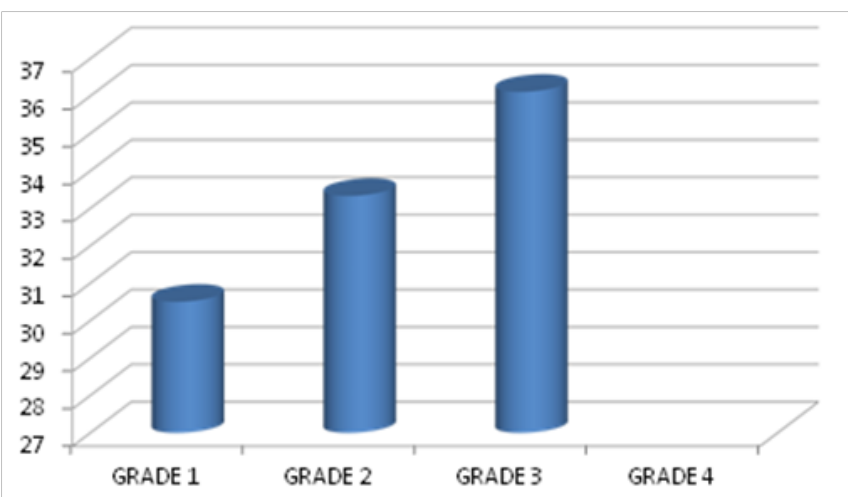

Figure 5 Percentage distribution hypoglycaemic episodes in type I diabetics in Africans. $(n=36)$

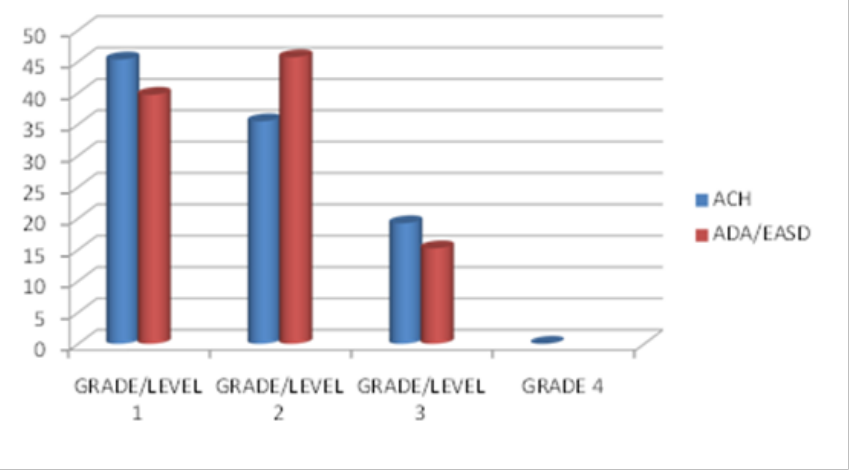

Figure 6 Comparison between Ademolus classification of hypocalcaemia $(A C H)(n=203)$ and American association for the study of diabetes (EASD) 2018 classification of hypocalcaemia $(n=197)$ in percentage.

\section{Discussion}

It is glaring from this African study that a grade 4 hypoglycemic episode is not recorded in African diabetics based on this study. The probable explaination is that grade 4 hypoglycemia does not exist or is rare in African diabetic as none was recorded over almost a decade of study as shown in this study. A larger multicenter study will help to expatiate further on this hypothesis.

It is known that people living with diabetes does not develop hypoglycemia at such a low level this may be the explaination for not finding grade 4 hypoglycemia in this African study.

Generally, the commonest grade of hypoglycemia in people living with diabetes in Africa is grade 1.The commonest grade of hypoglycemia in African living with type 2 diabetes mellitus is grade 1 while the commonest grade of hypoglycemia in Africans living with type 1 diabetes mellitus is grade 3 . The commonest grade in type 2 diabetes on insulin alone is grade 1.The commonest grade in type 2 on insulin and glucose lowering agent is grade 2 .

Grade 3 is the least common grade generally in African diabetics, in type 2 diabetics generally, in type 2 diabetics on insulin therapy alone, and also in type 2 diabetics on insulin and oral hypoglycemic agents. In contrast, the least common grade in Africans with type 1 DM is grade 1.

It is worth noting that the commonest grade of hypoglycemia in type 1 where patient is insulin deficient, ${ }^{10-12}$ is grade 3 since exogenous 
insulin therapy is available while in type 2 on insulin alone where there is insulin resistance, ${ }^{13,14}$ the commonest grade is grade 1 which is a milder form of hypoglycemic episodes. Meanwhile the commonest grade seen in type 2 diabetics on insulin and glucose lowering agents is grade 2, a moderate form of hypoglycemia due to additional effect of glucose lowering agents.

Approximately it can be said that one third of type 1 will have grade 1 , another third will have grade 2 while the last third will have grade 3 .

It is worth noting that the lowest hypoglycemic episode of a fasting blood sugar of $20 \mathrm{mg} / \mathrm{dl}$ among those with type 2 in this study was asymptomatic hypoglycemia. It was specifically noted in parenthesis in the case file that despite the low value, the patient is stable and had no symptom of hypoglycemia whatsoever. This goes to support the fact that asymptomatic hypoglycemia can occur in grade 3 even in diabetic patients!.

Among the type $1 \mathrm{DM}$ involved in this study, it is clearly shown that they can have grade 1 to 3 hypoglycemia, it is noted in this study that these different grades of hypoglycemia can occur in the same individual at different times, probably this is influenced by the dose, dosage of insulin the individual is on. A 19years old type $1 \mathrm{DM}$ subject involved in this study had a total of 18 (eighteen) episodes of hypoglycemia of different grades of hypoglycemia at different times during admission, $50 \%$ of these episodes were grade 2 hypoglycemia, $28 \%$ were grade 1 while $22 \%$ were grade 3 .In a patient like this, management will be made easier in studying appropriately the dose of insulin that gives the patient grade 3 , grade 2 and grade 1 hypoglycemia and adjusting the dose appropriately to come out of grade 1 hypoglycemia to a euglycemic state. This patient recovered from the 18episodes of hypoglycemia.

Another 35years old type 1 DM patient had 6episodes of hypoglycemia, $66.7 \%$ of these were grade $3,16.7 \%$ was grade 1 while $16.7 \%$ was grade 2 , she had 4 episodes of nocturnal hypoglycemia, these episodes were grade 3 , on an occasion, she recorded a symptomatic low value of $21 \mathrm{mg} / \mathrm{dl}$ at $1.00 \mathrm{a} . \mathrm{m}$; this is the grade with neuroglycopenic features majorly reversible; in this patient, there is the risk of the blood sugar falling further till irreversible brain damage occurs which can results in death; the occurrence at $1.00 \mathrm{a} . \mathrm{m}$ also suggest that diabetics could develop irreversible brain damage during sleep which could lead to death during sleep in diabetics. In this particular patient he survived this symptomatic hypoglycemic episode of low blood sugar value of $21 \mathrm{mg} / \mathrm{dl}$ following resurcitation. However almost 24hours later at $12.30 \mathrm{a} . \mathrm{m} \mathrm{He}$ went to another episode of grade 3 hypoglycemia with RBS $36 \mathrm{mg} / \mathrm{dl}$, he was resurcitated and recovered but at $10 \mathrm{pm}$ same day she went to another hypoglycemic episode (rebound hypoglycemia) with RBS of $40 \mathrm{mg} / \mathrm{dl}$ (grade 2) but did not respond to resurcitation with $50 \%$ dextrose water but progressed and died 30minutes later. This supports previous findings in literature that Hypoglycemia is also associated with increased morbidity, mortality and length of hospital stay. Though there was no record of autopsy, the repeated grades 3episodes of hypoglycemia she had was a major contributory factor clinically as the primary cause of death in this patient could possibly be from previous irreversible brain damage.

It is worth noting that this latter patient with occurrence of more severe episodes of hypoglycemia (66.7\% of all hypoglycemic episodes the patient experienced) died while the former with lesser episodes of severe hypoglycemia (only $22 \%$ of hypoglycemic episodes experienced) survived despite having more total episodes of hypoglycemia! This shows that frequent severe hypoglycemic episodes carries poorer prognosis in Africans.

A retrospective cohort study of patients with diabetes hospitalized in general wards showed that hypoglycemia $(<50 \mathrm{mg} / \mathrm{dl}$ or $2.8 \mathrm{mmol} / \mathrm{l})$ was associated with increased length of stay, and higher mortality both during admission and within 1year of discharge. ${ }^{15}$ Results from a large multicenter randomized controlled trial reported an overall increase in mortality in critically ill patients treated with intensive insulin therapy versus standard therapy. Results from this trial were influential in leading to recent guideline changes that emphasize less intensive glycemic targets for in patients. ${ }^{16,17}$ It is documented in literature that severe hypoglycemia secondary to hypoglycemia unawareness can cause neuronal cell death as seen in some of the cases highlighted above. $^{18-23}$

Severe episodes of hypoglycemia requiring the assistance of another have been shown to be associated with an increased risk of mortality in both the Action to Control Cardiovascular Risk in Diabetes (ACCORD), ${ }^{24}$ and the Action in Diabetes and Vascular Disease: Preterax and Diamicron Modified Release Controlled Evaluation (ADVANCE) studies. ${ }^{25,26}$

Though the duration of diabetic in relation to the grade a diabetic will develop was not looked into in this study as it is not the primary aim, yet it is worth noting that a 56year old type $1 \mathrm{DM}$ patient in the study who had long standing diabetes,${ }^{27}$ of over 20years and had been on insulin and had diabetes mellitus foot syndrome of the right foot only developed one episode of grade 1 hypoglycemia $(69 \mathrm{mg} / \mathrm{dl})$ while on admission. A study evaluating duration of diabetes and usual grades of hypoglycemia a diabetic can develop is suggested for future research in all ethnic groups.

The scientific fact also holds, as it was found in type 1 in this study, that grade 1,2 or 3 hypoglycemic can occur in the same patient with type 2 diabetes mellitus at different times. ${ }^{28,29}$

One of the type 2 diabetic patients in this study had a total of 24 episodes of hypoglycemia at different times; $50 \%$ of these were grade $1,29.2 \%$ were grade 2 while remaining $20.8 \%$ were grade 3 . Another subject had 18 episodes out of which $55.6 \%$ were grade $1,27.8 \%$ were grade 2 while $16.7 \%$ were grade 3 .

A 65year old type 2 diabetic on glimepiride and metformin alone presented with grade 2 hypoglycemia with seizure as the neuroglycopenic symptom, she had repeated reported (probable) hypoglycemic episodes, 40(forty) episodes were recorded while on admission. However with treatment, she recovered fully from the neuroglycopenic symptoms and was discharged, she obviously had a reversible neuroglycopenia. Full recovery from hypoglycemia without neurological sequalea is well documented in literature. ${ }^{30}$

Another 95year old type 2 diabetic presented with loss of consciousness and seizure .He had grade 2hypoglycemia on presentation, he was on glibenclamide, and He was resurcitated with $50 \%$ dextrose water and recovered. Two days later he had grade 1 hypoglycemia though uncounscious with no seizure, he was resurcitated and recovered. He was discharged in euglycemic state few days later. A study on hypoglycemia in the elderly diabetic and usual grade (s) found in them is suggested for future research in all ethnic group..$^{31-34}$ 
A 76year old newly diagnosed female diabetic had a symptomatic grade 3hypoglycemia while on admission however she was conscious, she was given glucose drink and fifteen minutes later her hypoglycemia had improved from grade 3 to grade 1, this goes to support the fact that in outpatients, hypoglycemia can be managed in the community with glucose drink prior to presentation to the physician. ${ }^{35}$

Another 70year old male diabetic presented with general body weakness and was semiconscious, he was found to have grade 3 hypoglycemia ,in such a patient, correlating his glascow coma score with the grade of hypoglycemia for prognostic purposes will be very helpful in drawing the line of management ${ }^{36}$ his glascow coma score was $15 / 15$ before discharge.

Another 72years old type 2 diabetic had seven episodes of hypoglycemia and all were grade 1 hypoglycemic episodes occurring at different times.

Another 79year old diabetic had three episodes of hypoglycemia from which she recovered fully while on admission but later died of hypoglycemia unrelated cause of death as she had co morbidity like cerebrovascular accidents, upper gastrointestinal bleeding and severe anaemia on admission. ${ }^{37,38}$

The ADA/EASD 2018classification of hypoglycemia put the commonest level of hypoglycemia in this African population as level $2(45.69 \%)$ followed by level 1 (39.09\%) then level $3(15.22 \%)$. Comparatively,(see Figure 6) ACH put the commonest grade of hypoglycemia as grade $1(45.32 \%)$, followed by grade $2(35.47 \%)$ then grade $3(19.21 \%)$. The differences in the findings of the two classification can be explained thus. Grade 1 which was commonest hypoglycemic episodes in $\mathrm{ACH}$ with 92episodes was reduced to 77 episodes by ADA/EASD 2018 classification because 6episodes had values of $70 \mathrm{mg} / \mathrm{dl}$ while the remaining 9episodes needed assistance with a cube of sugar or dextrose infusion from health workers while on admission these makes these 9episodes level 3. However it should be noted emphatically that if these nine episodes had occurred in a setting were healthcare management will had not been surrendered to a third part/health workers like in outpatient setting, the patient could have reached out for cubes of sugar or glucose drink on their own without a third party assistance making the hypoglycaemic episodes to be level 1 instead of level 3. This is a major setback/limitation of ADA/EASD 2018hypoglycemic classification as it makes virtually all symptomatic hypoglycaemia occurring in hospitalized patients as level three since it will require the assistance of health workers irrespective of its severity since the patient had surrendered their will on medical attention to medical staffs on admission!.

Grade 3 and level 3 were the least common form of hypoglycemia in this African study using both ACH and ADA/EASD 2018 classification respectively. However the percentages differ. ACH put it at $19.21 \%$ while ADA/EASD 2018 classification of hypoglycemia put it at $15.22 \%$. The reduction in percentages shows that the ADA/ EASD 2018 classification does not pick asymptomatic hypoglycemic episodes that are biochemically low in absolute value as severe hypoglycemia while ACH does. This deficiency of ADA/EASD 2018 classification is very dangerous prognostically in that it can result in preventable irreversible brain damage or sudden deaths perhaps, in patients in this category! Hence ACH cannot be neglected or jettisoned in the management of diabetics with hypoglycemia complicating their management for the benefit of the endocrine community.
One of the major strength of this article is that this is the first article in literature that analysed hypoglycemic episodes quatitatively/ objectively in diabetics in Africans using Ademolus Classification of Hypoglycemia. There are two Attempts to use it by previous authors, the first set of authors from Massachusetts General Hospital were limited by the lack of quatitative values of hypoglycemia in their study, as required in the classification just as it is required in Whipples triad, for statistical analysis. ${ }^{39}$ The Massachussets General Hospital authors stated that the Ademolus Classification of Hypoglycemia would have been a suitable method to classify the severity of hypoglycemic events; however, this classification system, like the Whipple's triad, required glucose levels during hypoglycemic episodes, which were not systematically recorded in electronic health record (EHR)". The second record of ACH use in literature was in a small study population of 10diabetic participants done in Minneapolis where hypoglycemia occurrence was compared in patients on U500 concentrated insulin administered via Disposable Patch Insulin Pump (DPIP) vs. Twice Daily Injections (BID) with insulin pen in a case series form in white population where In analyzing hypoglycemia data, the Minneapolis authors utilized definitions laid out by the 2018 American Diabetes Association (ADA) hypoglycemia classification system and Ademolus Classification of Hypoglycemia (ACH).They found that there were no ADA severe hypoglycemic episodes requiring external assistance for recovery throughout the course of their study. Similarly there were neither ACH grades 3 hypoglycemic episodes 10-39.9 mg/dL (severe hypoglycemia) nor $\mathrm{ACH}$ grade 4 hypoglycemic episodes $<10 \mathrm{mg} / \mathrm{dL}$ throughout the course of the study. ${ }^{40}$

Now 1 will suggest that in a future study the trend of hypoglycaemia seen over a long term period of suIphonyurea introduction into black race be studied using $\mathrm{ACH}$. The result it will give may be more objective and revealing than whatever we have now in literature.

\section{Conclusion}

Grade 4hypoglycemia was not recorded in both type 1 and type 2 diabetes mellitus in this African study. The commonest grade of hypoglycemia is grade 1 in type 2 and grade 3 in type 1 diabetics. The least common grade in type 2diabetes is grade 3 while in type 1 it is grade 1. A similar study is recommended in Americans, Europeans, Asians and all ethnic groups for possibly racial differences or disparity in the findings of this research.

\section{Acknowledgment}

None.

\section{Funding}

This study was not sponsored by any governmental or nongovernmental organization.

\section{Conflicts of interests}

Authors declare that there is no conflict of interest.

\section{References}

1. Elizabeth R, Seaquist, John Anderson, et al. Hypoglycemia and Diabetes: A Report of a Workgroup of the American Diabetes Association and The Endocrine Society. Diabetes Care. 2013;36(5):1384-1395.

2. Amiel SA, Sherwin RS, Simonson DC, et al. Effect of intensive insulin therapy on glycemic thresholds for counterregulatory hormone release. Diabetes. 1988;37:901-907. 
3. Dagogo-Jack SE, Craft S, Cryer PE. Hypoglycemia-associated autonomic failure in insulin-dependent diabetes mellitus. Recent antecedent hypoglycemia reduces autonomic responses to, symptoms of, and defense against subsequent hypoglycemia. J Clin Invest. 1993;91:819-828.

4. Davis SN, Shavers C, Mosqueda GR, et al. Effects of differing antecedent hypoglycemia on subsequent counterregulation in normal humans. Diabetes. 1997;46:1328-1335.

5. Heller SR, Cryer PE. Reduced neuroendocrine and symptomatic responses to subsequent hypoglycemia after 1 episode of hypoglycemia in nondiabetic humans. Diabetes. 1991;40:223-226.

6. Boyle PJ, Schwartz NS, Shah SD, et al. Plasma glucose concentrations at the onset of hypoglycemic symptoms in patients with poorly controlled diabetes and in nondiabetics. N Engl J Med. 1988;318:1487-1492.

7. Ademolu AB, Ademolu AO, Ogbera AO, et al. Hypoglycemia in lkorodu. Journal of Asian Health. 2015.

8. Ademolu AB. Role of Ademolus Classification of Hypoglycemia in Blood Glu-cose and Diabetes Mellitus Management. Gastroenterol Liver Clin Med. 2017;1:1-3.

9. American Diabetes Association. Standards of Medical Care in Diabetes-2019. Diabetes Care. 2019;42(1):1-2.

10. American Diabetes Association. Diagnosis and Classification of Diabetes Mellitus. Diabetes Care.2009;32(1):62-67.

11. Mark A Atkinson, George S Eisenbarth, Aaron W Michels. Type 1 diabetes. Lancet. 2014;383(9911):69-82.

12. Lindy Kahanovitz, Patrick M. Sluss and Steven J Russell Type 1 Diabetes - A Clinical Perspective. Point Care. 2017;16(1):37-40.

13. Roy Taylor. Insulin Resistance and Type 2 Diabetes. Diabetes. 2012;61(4):778-779.

14. Kara Mizokami S, Melanic Cree Green, Kristen J Nadean. Insulin resistance in type 2 diabetic youth. Curr Opin Endocrinol Diabetes Obes. 2012;19(4):255-262.

15. Turchin A, Matheny ME, Shubina M, et al. Hypoglycemia and clinical outcomes in patients with diabetes hospitalized in the general ward. Diabetes Care. 2009;32(7):1153-1157.

16. Finfer S, Liu B, Chittock DR, et al. Hypoglycemia and risk of death in critically ill patients. $N$ Engl J Med. 2012;367(12):1108-1118.

17. Raphael DH, Rena MP, Joel Z .Understanding hypoglycemia in hospitalized patients. Diabetes Manag (Lond). 2014;4(2):165-176.

18. Holstein A, Egberts EH. Risk of hypoglycaemia with oral antidiabetic agents in patients with Type 2 diabetes. Exp Clin Endocrinol Diabetes. 2003;111:405-414.

19. Amiel SA, Dixon T, Mann R, Jameson K. Hypoglycaemia in Type 2 diabetes. Diabet Med. 2008;25:245-254.

20. Marrett E, Radican L, Davies MJ, et al. Assessment of severity and frequency of self-reported hypoglycemia on quality of life in patients with type 2 diabetes treated with oral antihyperglycemic agents: A survey study. BMC Res Notes. 2011;4:251

21. Whitmer RA, Karter AJ, Yaffe K, et al. Hypoglycemic episodes and risk of dementia in older patients with type 2 diabetes mellitus. JAMA. 2009;301:1565-1572.

22. Allen KV, Frier BM. Nocturnal hypoglycemia: clinical manifestations and therapeutic strategies toward prevention. Endocr Pract. 2003;9:530543 .
23. Iciar MT, Francisco JC. Mechanisms of hypoglycemia unawareness and implications in diabetic patients. World J Diabetes. 2015; 6(7):912-926.

24. Gerstein HC, Miller ME, Byington RP, et al. Action to Contro Cardiovascular Risk in Diabetes Study Group Effects of intensive glucose lowering in type 2 diabetes. N Engl J Med. 2008;358:25452559 .

25. Zoungas S, Patel A, Chalmers J, et al. ADVANCE Collaborative Group Severe hypoglycemia and risks of vascular events and death. $N$ Engl $J$ Med. 2010;363:1410-1418.

26. Elizabeth R, Seaquist, Michael E, et al. The Impact of Frequent and Unrecognized Hypoglycemia on Mortality in the ACCORD Study. Diabetes Care. 2012;35(2):409-414

27. Gita Shafiee, Mohammadreza MT, Mohammad P, et al. The importance of hypoglycemia in diabetic patients. Journal of Diabetes \& Metabolic Disorders. 2012;11:17.

28. Richa RG, Godwin Y, Dogbey, et al. Hypoglycemia in Type 2 Diabetes - More Common Than You Think. A Continuous Glucose Monitoring Study. J Diabetes Sci Technol. 2015;9(5):999-1005.

29. Alok Kumar. Recurrent hypoglycaemia in type 2 diabetic patient due to hypothyroidism. J Diabetes Metab Disord. 2015;14:13.

30. Pankaj Seth, Amit Bery, Arun Kumar Gupta. Clinical Profile of Hypoglycemia in Diabetic Patients: A Prospective Study in a Tertiary Care Hospital. AJRIMPS. 2018;4(1):1-7.

31. Mousumi S, Ashmeet B, Medha M. Review of Hypoglycemia in the Older Adult: Clinical Implications and Management. Can J Diabetes. 2016;40:66-72.

32. Ahmed HA, Leocadio RM, John E. Morley and Alan J Sinclair Hypoglycemia in Older People - A Less Well Recognized Risk Factor for Frailty. Aging Dis. 2015;6(2):156-167.

33. Avila FFM, Montana AM. Hypoglycemia in the elderly with diabetes mellitus. Rev Invest Clin. 2010;62(4):366-374

34. Ruth S. Weinstock, Stephanie N, et al. Risk Factors Associated With Severe Hypoglycemia in Older Adults With Type 1 Diabetes. Diabetes Care. 2015;151426.

35. Javier Morales, Doron S. Hypoglycemia. The American Journal of Medicine. 2014;10:17-24.

36. Atsushi Kotera, Shinsuke Iwashita, Hiroki Irie, et al. An analysis of the relationship between Glasgow Coma Scale score and plasma glucose level according to the severity of hypoglycaemia. $J$ Intensive Care.2014;2(1):1.

37. Elbert SH. Management of diabetes mellitus in older people with comorbidities. BMJ. 2016;353:2200.

38. Caughey GE, Roughead EE, Vitry AI, et al. Comorbidity in the elderly with diabetes: Identification of areas of potential treatment conflicts. Diabetes Res Clin Pract. 2010;87(3):385-393.

39. Leong A, Berkowitz SA, Triant VA, et al. Hypoglycemia in Diabetes Mellitus as a Coronary Artery Disease Risk Factor in Patients at Elevated Vascular Risk. J Clin Endocrinol Metab. 2016;101(2):659-668.

40. Christopher M, Favid PM, Muhammad S, et al. U500 Disposable Patch Insulin Pump: Results and Discussion of a Veteran Affairs Pilot Study. $J$ Endocr Soc. 2018;2(11):1276-1283. 